\title{
Application of Drying Techniques in Food Processing
}

\author{
Shraddha Bhople*, Mohan Singh and Devendra Kumar Verma \\ Department of Post-harvest Process and Food Engineering, JNKVV Jabalpur (M.P), India \\ *Corresponding author
}

\section{Keywords}

drying method, sun drying, solar drying, spray drying, freeze drying.

\section{Article Info}

Accepted: 07 July 2019 Available Online: 10 August 2019

\section{A B S T R A C T}

Drying is one of the oldest preservation processes available to the mankind, on that we can track since prehistoric times. In today food market dried foods play an important role in the food supply chain. As for fruits and vegetables it can be estimated that they constitute about $1 \%$ of the total drying in the food industry, by large being the grains the most important. The main feature of this process consists on lowering the water content in order to avoid or slow down food spoilage by microorganism. At this point some understanding can arise derived from the vocabulary employed; common words found are "drying" or "dehydration", or even "dewatering". There are various aspects that must be considered when drying small fruits and vegetables, whether for the food or nutraceutical and functional food industries. A system which minimizes exposure to light, oxidation and heat, (i.e. high heat $70 \mathrm{oC}$ and shorter time duration) may help conserve critical bioactive compounds. This review focuses upon new drying technologies.

\section{Introduction}

Food drying is method of food preservation in which food is dried (dehydrated or desiccated). Drying inhibits the growth of bacteria, yeasts and mould through the removal of water. Water is traditionally removed through evaporation (air drying, sun drying, smoking or wind drying), although today electric food dehydrators or freeze drying can be used to speed the drying process and ensure more consistent results.

\section{Drying process}

Drying processes fall into three following

Air and contact drying under atmospheric pressure. In air and contact drying,

Heat is transferred through the foodstuff either from heated surfaces.

Vacuum occurs more readily at lower pressures than higher ones. 
Freeze drying. In freeze drying, the water vapor is submitted off frozen food. The food structure is better maintained under these conditions. Suitable temperatures and pressures must be established in the dryer to ensure that sublimation occurs.

\section{Drying mechanism}

Drying involves heat and mass transfer principles. Heat is transfer to the product to evaporate liquid and mass is transferred as a vapor into surrounding gas.

\section{Rate of drying}

Drying operation may be done with constant rate and falling rate depends on its critical moisture content. In some products having relatively high initial moisture content, an initial linear reduction of the average product moisture content as a function of time may be observed for a limited time, often known as a "constant drying rate period". Usually in this period, it is surface moisture outside individual particles that is being removed. The drying rate during this period is mostly dependent on the rate of heat transfer to the material being dried. Therefore, the maximum achievable drying rate is consider to be heat transfer limited. If drying is continued, the slope of the curve, the drying rate becomes less steep (falling rate period) and eventually tends to nearly horizontal at very long times. The product moisture content is then constant at the "equilibrium moisture content, where it is, in practice, in equilibrium with the dehydrating medium.

In the falling rate period, water migration from the product interior to the surface is mostly by molecular diffusion, i.e. the water flux is proportional to the moisture content gradient. This means that water moves from zones with higher moisture content to zones with lower values, a phenomenon explained by second law of thermodynamics. If water removal is considerable, the products usually undergo shrinkage and deformation, except in a well-designed freeze - drying process.

\section{Types of drying}

Sun drying: sunlight is a portion of the electromagnetic radiation given off by the sun, in particular infrared, visible and ultraviolet light.

Tray drying: The dryers are made of trays held in a cabinet which is connected to a source of air heated by gas, diesel or biomass such as rice husk.

Tunnel drying: The tunnel dryer is a modification of tray dryer in which the oven is replaced by a tunnel which receives damp materials at one end and discharges the dried products at the other end.

Roller or Drum drying: Drum drying is a method used for drying out liquids from raw materials with drying drum. In the drum drying process, pureed raw ingredients are dried at relatively low temperatures over rotating, high capacity drums that produce sheets of drum dried product.

Fludized bed drying: Fludized bed drying is the optional method for controlled, gentle and even drying of wet solids.

Spray Drying: Spray Drying is a method of producing dry powder from a liquid or slurray by rapidly drying with a hot gas.

Pneumatic Drying: Pneumatic or flash dryers one of the most common types of industrial drying units, are characterized by continuous convective heat and mass transfer processes.

Rotary Drying: Rotary Drying and cooling equipment utilize a hot gas stream or colg gas 
stream, that mixes with the air stream by utilizing lifters that showers the product in the air stream.

Tough Dryer: In Tough Dryer, the materials to be dried are conteined in a trough - shaped conveyor belt, made from mesh, and air is blown through the bed of material. The movements of conveyor continually turn over the material, exposing fresh surfaces to the hot air.

Belt Drying: Belt Drying is a continuous convective belt dryer. A well - ventilated layer of product is put on a wire mesh or perforated plate belt conveyor and conveyed continuously through drying chamber.

Vacuum Drying: In Vacuum Drying, the pressure is reduced around the substance to be dried and boiling point of water inside that product decreases and rate of evaporation of water increases significantly thus increasing drying rate. The pressure maintained in vacuum drying is generally $0.0296-0.059$ atm and the boiling point of water is $25-30$ Oc. The vacuum drying is batch operation and at reduced a pressure the relative humidity is also lower and that is why the drying occurs faster.

Freeze Drying: Freeze Drying or lyophilisation is a drying method where the solvent is frozen prior to drying and is then sublimet, i.e., passed to the gas phase directly from the solid phase, below the melting point of the solvent.

Drying techniques used for reduce moisture content and concentrating the food products. The reducing in water content may leads to decrease the growth of microorganism which prevents the food spoilage. Reduction in water content may also prevent the additional transport cost etc. the article can be concluded that the use of drying technique in food industry is essential method.

\section{References}

Anupam Tiwari, A Review on Solar Drying of Agricultural Produce, J Food Process Technol 7: 623. doi: 10.4172/21577110.1000623.

Daniel Maisnam, Prasad Rasane, Anirban Dey, Sawinder Kaur, Chayanika Sarma, Recent advances in conventional drying of foods, J Food Technol Pres. 2017; 1: 25-34.

K.J. Chua and S.K. Chou, Low-cost drying methods for developing countries, Trends in Food Science \& Technology 14 (2003) 519-528.

Sunil Jayant Kulkarni, Ajaygiri Kamalgiri Goswami, Application, Advancements and Research on Drying- A Review, IJRASET Volume 3 Issue VIII, August 2015 ISSN: 2321-9653.

\section{How to cite this article:}

Shraddha Bhople, Mohan Singh and Devendra Kumar Verma. 2019. Application of Drying Techniques in Food Processing. Int.J.Curr.Microbiol.App.Sci. 8(08): 556-558. doi: https://doi.org/10.20546/ijcmas.2019.808.066 